\title{
A multicentric quality-control study of exercise Doppler echocardiography of the right heart and the pulmonary circulation
}

Francesco Ferrara ${ }^{1}$, Luna Gargani ${ }^{1}$, Carla Contaldi ${ }^{1}$, Gergely Agoston ${ }^{1}$, Paola Argiento ${ }^{2}$, William Armstrong ${ }^{3}$, Rodolfo Citro ${ }^{4}$, Antonio Cittadini ${ }^{1}$, Rosangela Cocchia ${ }^{1}$, Michele D'Alto $^{2}$, Antonello D'Andrea ${ }^{5}$, Philippe Douschan ${ }^{1}$, Stefano Ghio ${ }^{6}$, Ekkehard Grünig ${ }^{7}$, Marco Guazzi ${ }^{8}$, Jaroslaw Kasprzak ${ }^{9}$, Theodore Kolias ${ }^{3}$, Alberto Marra ${ }^{1}$, Antonella Moreo $^{10}$, Francesco Pieri ${ }^{1}$, Lorenza Pratali ${ }^{11}$, Brigida Ranieri ${ }^{1}$, Lawrence Rudski ${ }^{1}$, Valentina Russo $^{1}$, Rajan Saggar ${ }^{1}$, Anna Agnese Stanziola ${ }^{1}$, Mani A. Vannan ${ }^{12}$, Olga Vriz ${ }^{13}$, Robert Naeije ${ }^{1}$, and Eduardo Bossone ${ }^{14}$

${ }^{1}$ Affiliation not available

${ }^{2}$ Second University of Naples - Monaldi Hospital

${ }^{3}$ University of Michigan

${ }^{4}$ A.O.U. San Giovanni di Dio e Ruggi d'Aragona

${ }^{5}$ Second University of Naples

${ }^{6}$ Fondazione IRCCS Policlinico San Matteo

${ }^{7}$ Thoraxclinic at the University Hospital Heidelberg

${ }^{8}$ IRCCS

${ }^{9}$ Medical University of LodzII

${ }^{10}$ Niguarda Cà Granda Hospital

${ }^{11}$ National Center of Research (CNR)

${ }^{12}$ Ohio State Univ

${ }^{13}$ San Antonio Hospital

${ }^{14}$ ASL Salerno

May 18, 2020

\begin{abstract}
Purpose: This study was a quality-control study of resting and exercise echocardiography (EDE) variables measured by 19 echocardiography laboratories with proven experience participating in the RIGHT Heart International NETwork. Methods: All participating investigators reported the requested variables from ten randomly selected exercise stress tests. Intraclass correlation coefficients (ICC) were calculated to evaluate the inter-observer agreement with the core laboratory. Inter-observer variability of resting and peak exercise tricuspid regurgitation velocity (TRV), right ventricular outflow tract acceleration time (RVOT Act), tricuspid annular plane systolic excursion (TAPSE), tissue Doppler tricuspid lateral annular systolic velocity (S'), right ventricular fractional area change (RV FAC), left ventricular outflow tract velocity time integral (LVOT VTI), mitral inflow pulsed wave Doppler velocity (E), diastolic mitral annular velocity by TDI (e') and left ventricular ejection fraction (LVEF) was measured. Results: The accuracy of 19 investigators for all variables ranged from $99.7 \%$ to $100 \%$. ICC was $>$ 0.80 for all observers. Inter-observer variability for resting and exercise variables was for TRV $=3.8$ to $2.4 \%, \mathrm{E}=5.7$ to $8.3 \%$, $\mathrm{e}^{\prime}=6$ to $6.5 \%$, RVOT Act $=9.7$ to 12 , LVOT VTI $=7.4$ to $9.6 \%, \mathrm{~S}^{\prime}=2.9$ to $2.9 \%$ and TAPSE $=5.3$ to $8 \%$. Moderate inter-observer variability was found for resting and peak exercise RV FAC (15 to 16\%). LVEF revealed lower resting and peak exercise variability of 7.6 and $9 \%$. Conclusions: When performed in expert centers EDE is a reproducible tool for the assessment
\end{abstract}


of the right heart and the pulmonary circulation

A multicentric quality-control study of exercise Doppler echocardiography of the right heart and the pulmonarycirculation

Francesco Ferrara ${ }^{1}$, MD, Luna Gargani ${ }^{2}$, MD, Carla Contaldi ${ }^{1}, \mathrm{MD}, \mathrm{PhD}$, Gergely Agoston $^{3}$, MD, Paola Argiento $^{4}$, MD, William F Armstrong ${ }^{5}$, MD, Francesco Bandera ${ }^{6}$, MD, Rodolfo Citro ${ }^{1}$, MD, PHD, Antonio Cittadini $^{7}, \mathrm{MD}, \mathrm{PhD}$, Rosangela Cocchia ${ }^{8}, \mathrm{MD}$, Michele D'Alto ${ }^{4}, \mathrm{MD}, \mathrm{PhD}$, Antonello D'Andrea ${ }^{9}, \mathrm{MD}$, $\mathrm{PhD}$, Philippe Douschan ${ }^{10}$, MD, Stefano Ghio ${ }^{11}$, MD, PhD, Ekkehard Grunig ${ }^{12}$, MD, Marco Guazzi ${ }^{6}$, MD, PhD, Stefania Guida ${ }^{11}$, MD, Jaroslaw D. Kasprzak ${ }^{13}$, MD, Theodore John Kolias ${ }^{5}$, MD, Alberto Maria Marra $^{7}, \mathrm{MD}, \mathrm{PhD}$, Matteo Mazzola ${ }^{2}$, MD, Antonella $\mathrm{Moreo}^{14}$, MD, Francesco Pieri ${ }^{15}$, MD, Lorenza Pratali ${ }^{2}$, MD, PhD, Nicola Riccardo Pugliese ${ }^{16}, \mathrm{MD}$, Mauro Raciti ${ }^{2}, \mathrm{MD}$, Brigida Ranieri ${ }^{17}, \mathrm{PhD}$, Lawrence Rudski ${ }^{18}$, MD, Valentina Russo ${ }^{19}$, MD, Rajan Saggar ${ }^{20}$, MD, Walter Serra ${ }^{21}$, MD, PhD, Anna Agnese Stanziola ${ }^{22}$, MD, PhD, Mani Vannan ${ }^{23}$, MD, Damien Voilliot ${ }^{24}$, MD, Olga Vriz ${ }^{25}$, MD, Karina Wierzbowska Drabik ${ }^{13}$, MD, Robert Naeije ${ }^{26}, \mathrm{MD}$, Eduardo Bossone ${ }^{8}, \mathrm{MD}, \mathrm{PhD}$. On behalf of the RIGHT Heart International NETwork (RIGHT-NET).

1 Cardio-Thoracic-Vascular Department, University Hospital "San Giovanni di Dio e Ruggi d'Aragona", Salerno, Italy

${ }^{2}$ Institute of Clinical Physiology - C.N.R., Pisa, Italy

${ }^{3}$ Department of Family Medicine, Faculty of Medicine, University of Szeged; Szeged-Hungary

${ }^{4}$ Department of Cardiology, University of Campania "Luigi Vanvitelli", Naples, Italy

${ }^{5}$ Division of Cardiovascular Medicine, University of Michigan Medical Center, Ann Arbor, Michigan, USA

${ }^{6}$ Heart Failure Unit and Cardiopulmonary Laboratory, IRCCS Policlinico San Donato University Hospital, Milan, Italy Heart Failure Unit, Cardiology University Department, IRCCS Policlinico San Donato, Milan, Italy; Department for Biomedical Sciences for Health, University of Milano, Milan, Italy

${ }^{7}$ Department of Translational Medical Sciences, Federico II University, Naples, Italy

${ }^{8}$ Cardiology Division, A Cardarelli Hospital, Naples, Italy

${ }^{9}$ Department of Cardiology, Umberto I ${ }^{\circ}$ Hospital Nocera Inferiore, Italy

${ }^{10}$ Medical University of Graz, Graz, Austria

11 Division of Cardiology, Fondazione IRCCS Policlinico San Matteo, Pavia, Italy

12 Center of Pulmonary Hypertension, Thoraxklinik Heidelberg at Heidelberg University Hospital, Germany

${ }^{13}$ I Dept. and Chair of Cardiology, Bieganski Hospital, Medical University of Lodz, Poland

${ }^{14}$ A. De Gasperis Cardio Center, ASST Grande Ospedale Metropolitano Niguarda, Milan, Italy

15 Cardiology Department, Careggi University Hospital, Florence, Italy

${ }^{16}$ Department of Clinical and Experimental Medicine, University of Pisa, Italy

${ }^{17}$ IRCCS SDN, Naples, Italy

18 Azrieli Heart Center and Center for Pulmonary Vascular Diseases, Jewish General Hospital, McGill University, Montreal, Quebec, Canada

${ }^{19}$ Hypertension Research Center, University Federico II of Naples, Italy

${ }^{20}$ Lung \& Heart-Lung Transplant and Pulmonary Hypertension Programs David Geffen School of Medicine, UCLA, USA 
21 Cardiology Division, University Hospital, Parma, Italy

22 Department of Respiratory Diseases, Monaldi Hospital, University "Federico II", Naples, Italy

23 Piedmont Heart Institute, Marcus Heart Valve Center, Atlanta

24 Centre Hospitalier Lunéville, Service de Cardiologie, Lunéville, France

${ }^{25}$ Heart Centre, King Faisal Specialist Hospital and Research Centre, Riyadh, Saudi Arabia

${ }^{26}$ Free University of Brussels, Brussels, Belgium

\title{
Address for correspondence:
}

Eduardo Bossone, MD, PhD

Director, Cardiology Division, A Cardarelli Hospital, Naples, Italy

Via Pr. Amedeo, 36 - 83023 Lauro (AV), Italy Fax +39-081-8240067; Cell. +39- 328-5415438; email: ebossone@hotmail.com

\begin{abstract}
Purpose: This study was a quality-control study of resting and exercise echocardiography (EDE) variables measured by 19 echocardiography laboratories with proven experience participating in the RIGHT Heart International NETwork. Methods: All participating investigators reported the requested variables from ten randomly selected exercise stress tests. Intraclass correlation coefficients (ICC) were calculated to evaluate the inter-observer agreement with the core laboratory. Inter-observer variability of resting and peak exercise tricuspid regurgitation velocity (TRV), right ventricular outflow tract acceleration time (RVOT Act), tricuspid annular plane systolic excursion (TAPSE), tissue Doppler tricuspid lateral annular systolic velocity $\left(\mathrm{S}^{\prime}\right)$, right ventricular fractional area change (RV FAC), left ventricular outflow tract velocity time integral (LVOT VTI), mitral inflow pulsed wave Doppler velocity (E), diastolic mitral annular velocity by TDI (e') and left ventricular ejection fraction (LVEF) was measured. Results: The accuracy of 19 investigators for all variables ranged from $99.7 \%$ to $100 \%$. ICC was $>0.80$ for all observers. Inter-observer variability for resting and exercise variables was for $\mathrm{TRV}=3.8$ to $2.4 \%, \mathrm{E}=5.7$ to $8.3 \%$, e' $=6$ to $6.5 \%$, RVOT Act $=9.7$ to 12 , LVOT VTI $=7.4$ to $9.6 \%, \mathrm{~S}^{\prime}=2.9$ to $2.9 \%$ and TAPSE $=5.3$ to $8 \%$. Moderate inter-observer variability was found for resting and peak exercise RV FAC (15 to 16\%). LVEF revealed lower resting and peak exercise variability of 7.6 and $9 \%$. Conclusions: When performed in expert centers EDE is a reproducible tool for the assessment of the right heart and the pulmonary circulation.
\end{abstract}

Key words: right ventricle, pulmonary hypertension, exercise echocardiography

\section{Background}

Exercise Doppler echocardiography (EDE) is standard practice for the evaluation of patients with coronay artery disease. The procedure is now increasingly used for the assessment of right heart and the pulmonary circulation. $^{1-5}$ However, this technique may be limited, by its understudied inter-observer variability, which may impact on the quality and consistency of diagnostic results. The RIGHT Heart International NETwork (RIGHT-NET) study protocol incorporates a limited number of basic and generally accessible EDE measurements. ${ }^{6,7}$ Echocardiography of the pulmonary circulation basically relies on estimates of the components of the pulmonary vascular resistance equation, that is pulmonary artery pressure (PAP) from the maximum tricuspid regurgitation velocity (TRV), or the right ventricular outflow tract (RVOT) acceleration time (Act) of PA flow, wedged PAP from the ratio of transmitral flow E and mitral annulus e' waves and cardiac output (CO) from the left ventricular outflow tract (LVOT) aortic flow. Echocardiography of the right heart relies on estimates of right ventricular surface areas, tricuspid annular plane systolic excursion 
(TAPSE) and of tissue Doppler-derived tricuspid lateral annular systolic velocity (S'). ${ }^{2,3}$ The present report aims to validate the quality control process of the right heart and pulmonary circulation resting and exercise echo-Doppler variables and harmonize reading criteria among 19 echocardiography laboratories with proven experience participating in the RIGHT-NET study. ${ }^{6,7}$

\section{Methods}

The echo core Lab of the Institute of Clinical Physiology-CNR in Pisa (LG) coordinated the quality control procedure of all investigators at different centres participating in the RIGHT-NET study. Each center designated one operator that performed or reported at least 100 stress echocardiography studies per year. All readers were certified by national and/ or international societies. The quality control process was designed to be simple, repeatable, and sustainable. The Echo Core Lab issued a User Manual with a detailed description on how to measure each parameter, according to the most recent American and European Recommendations and Guidelines. ${ }^{8-11}$ The User Manual was sent to all Participating Centers including the reference for transthoracic echocardiography assessment. All participating centers followed the recommended standard operational procedures in terms of data data storage (data format, transfer procedure), and data processing (software used and measurement procedures). All operators performing and reading echocardiographic exams adhered to the quality control protocol. The Echo Core Lab sent ten complete echocardiographic examinations in DICOM format through a safe file sharing platform (Fig. 1). All participating investigators were invited by email to join the platform, which was protected by user-specific passwords. The platform includes also detailed instructions on how to start the training and allows downloading and uploading of external files. All images and videos were completely anonymized to protect patients' privacy, according to the new EU directive of protection of personal data (GDPR). ${ }^{6}$

\section{Reading sessions}

We randomly selected 10 cases including healthy subjects and at least one group of patients with overt and/or at risk of pulmonary hypertension $(\mathrm{PH})$, according to clinical classification of PH(Table 1) . ${ }^{12}$ Data were collected on patients undergoing EDE on a semi-recumbent cycle ergometer with an incremental workload of 25 Watts every 2 minutes up to the symptom-limited maximal tolerated workload including resting, 50 Watts, peak stress and recovery acquisition, as previously described. ${ }^{6}$ All operators directly measured the requested parameters by uploading the same ten cases from the web platform to their echocardiography machine. The DICOM format enabled to perform assessment of variables in the respective centres. All operators were then asked to enter their measurements in a dedicated excel file, which was then sent to the Coordinating Center for analysis. Table 2 provides the list of the left and the right heart parameters measured by all operators. The gold standard value for each measurement was established by the values measured by the Echo Core Lab.

Statistical analysis

Statistical analysis was performed using standard software (MedCalc version 14.8.1, MedCalc Software Ltd, Belgium; SPSS version 20.0, SPSS, Inc., Chicago, IL). Continuous variables were described by mean values \pm standard deviation (SD). Accuracy (in \%) for each observer was estimated by comparison with the reference standard (core lab reading). Intra-class correlation coefficient (ICC) was calculated along with the $95 \%$ confidence interval, in order to quantify the reliability of measurement process. An ICC of $>0.8$ indicated excellent agreement with the core lab. Inter-observer variability among 19 observers were examined for resting and peak exercise TRV, RVOT Act, TAPSE, S', right ventricular fractional area change (RV FAC), LVOT velocity time integral (VTI), mitral early inflow pulsed wave Doppler velocity (E), early diastolic mitral annular lateral and septal velocity by TDI (e'), left ventricular ejection fraction (LVEF). Data are presented as mean of the absolute and relative differences (in \%) between measurements.

Intra-observer agreement was tested in 2 observers who volunteered to repeat the measurement session on 2 separate days and ICC was calculated.

\section{Results}


Nineteen observers completed all reading sessions. Figure 2shows a summary of the accuracy (in \%) of each center compared with the gold standard core lab for all parameters at rest and at peak of exercise. The average accuracy of 19 readers for all parameters was excellent in about 99.8\% (range from 99.7\% to 100\%) (Table 3) . ICC was $>0.8$ for all observers. The average agreement of the 19 readers for all parameters was excellent $(\mathrm{ICC}=0.98)$. Moreover the average agreement among readers remained excellent at rest and at peak exercise for all measurements (ICC $=0.98$ and 0.99, respectively) (Table 4). Inter-observer variabilities for main exercise TTE measurements are reported in table 5 . Close inter-observer variabilities were found for both resting and peak exercise TRV (3.8 and 2.4\%), RV S' (2.9 and 2.9\%), E (5.7 and 8.3\%) and e' (6 and 6.5\%). Inter-observer variabilities of the RVOT Act and LVOT VTI were of 9.7 and $7.4 \%$ at rest, 12 and $9.6 \%$ at peak exercise, respectively. TAPSE showed less resting $(5.3 \%)$ than peak exercise variability (8\%). Moderate inter-observer variability was found for resting and peak exercise RV FAC (15 and 16\%, respectively). On the other hand LVEF revealed lower resting and peak exercise mean relative differences of 7.6 and $9 \%$, respectively.

The intra-observer quality control analysis revealed an excellent ICC of 0.97 (95\% Confidence Interval: 0.96 to 0.99$)$.

\section{Discussion}

Before any acquisition of pooling echocardiographic data for research and clinical applications, a process of quality control and reading harmonization measurements should be undertaken. ${ }^{13-16}$ The present results demonstrate that a rigoroursly designed protocol with a strong focus on quality assurance and certification can yield very strong ICC and limited variability among the 19 participant experienced centers to a large prospective EDE study of the right heart and the pulmonary circulation.

\section{Previous studies}

The inter-observer variability during EDE right heart and pulmonary circulation studies may be not negligible. Few such studies have been previously reported and all were mono-centric. ${ }^{3,17}$ Argiento et al reported in 124 healthy subjects (62 women and 62 men; age $37 \pm 13$ yrs) (single center study) an inter-observer variability for pulmonary artery systolic pressure (PASP) and cardiac output (CO) estimates of $1.9 \%$ and $4.9 \%$ at rest, and $7.9 \%$ and $13.9 \%$ at maximum exercise, respectively. ${ }^{18} \mathrm{D}$ 'Alto et al reported in 90 healthy subjects (45 male, mean age $39 \pm 13$ years) inter-observer variabilities between two readers at rest and peak exercise of $1.9 \%$ and $7.9 \%$ for PASP, $4.9 \%$ and $13.9 \%$ for stroke volume, $2.6 \%$ and $6.8 \%$ for TAPSE, and $5.4 \%$ and $8.7 \%$ for S', respectively. ${ }^{19}$ Kusunose et al reported in a subgroup of 15 randomly selected subjects with isolated moderate to severe mitral regurgitation a close inter- and intra-observer variability for resting TAPSE $(8.8 \%)$ and exercise TAPSE $(9.5 \%) .{ }^{20}$ As these data remain limited, more validation appeared necessary for a multi-centric study like the RIGHT-NET.

\section{Uniqueness of the present study and clinical implications}

To the best of our knowledge, this is the large EDE multicenter study that comprehensively provides a detailed quality control analysis of both the right heart and the pulmonary circulation measurements. One major finding was that the accuracy and agreement were remarkably high among 19 experienced investigators, with no significant differences between resting and exercise measurements. These results provide a valid evidence of reliability of TRV, E/e' ratio and LVOT VTI during exercise. The inter-observer variability of RVOT Act was higher than that of TRV. RVOT Act measurements were collected during exercise, in keeping with a recent report advocating its combination with TRV for the assessment of the pulmonary pressures both at rest and during exercise. ${ }^{21}$ The interest of this combination is that the feasibility rate of RVOT Act may be higher than that of TRV. ${ }^{22}$ Furthermore our findings suggested that exercise TAPSE and S' may be used as reproducible measures of the RV longitudinal systolic function. Larger resting and exercise variability of RV FAC may be caused by plane-dependency and reliance on difficult definition RV endocardial border. ${ }^{23}$

\section{Study limitations}

The present study did not validate the echocardiographic measurements against invasive gold standard eva- 
luation of the pulmonary circulation by PAP, wedged PAP and cardiac output, and right ventricular function by indices derived from pressure-volume loops. Thus accuracy and precision were defined by comparison only with the core laboratory measurements. The number of patients studied was relatively small $(\mathrm{n}=10)$. However, each of the 19 participating centers provided a total of 35 left and right heart echo-Doppler variables at rest, peak exercise and after 5 minutes of recovery. Finally, it should be underlined that contrast and/or agitated saline enhancement for tricuspid regurgitation (TR) Doppler signal was not performed. The additional use of contrast and/or agitated saline may further improve the reliability, particularly in less experienced centers.

\section{Conclusions}

When protocols for acquisition and analysis are provided upfront and in experienced echocardiography laboratories EDE represents a reproducible tool to comprehensively assess the right heart and pulmonary circulation. This quality control study represents a solid bedrock for future RIGHT-NET studies, aiming to evaluate the diagnostic and prognostic role of EDE in the clinical settings of patients with cardiorespiratory diseases.

\section{Figure Legend}

Figure 1. Quality control procedure

Figure 2. Accuracy of each center compared with the gold standard core lab for all, right and left parameters (A), for all parameters at rest and peak (B), for right paramaters at rest and at peak (C) and for left parameter at rest and at peak $(\mathrm{D})$.

\section{Appendix}

\section{The RIGHT Heart International NETwork (RIGHT-NET)}

\section{Investigators}

Co-Principal Investigators: Eduardo Bossone (A Cardarelli Hospital, Naples, Italy), Luna Gargani (Institute of Clinical Physiology, CNR, Pisa, Italy), Robert Naeije (Free University of Brussels, Brussels, Belgium).

Study Coordinator: Francesco Ferrara (Cava de' Tirreni and Amalfi Coast Division of Cardiology, University Hospital, Salerno, Italy)

Co-Investigators: William F. Armstrong, Theodore John Kolias (University of Michigan, Ann Arbor, USA); Eduardo Bossone, Rosangela Cocchia, Chiara Sepe (A Cardarelli Hospital, Naples, Italy); Francesco Capuano (Department of Industrial Engineering, Università di Napoli Federico II, Naples, Italy); Rodolfo Citro, Rossella Benvenga, Michele Bellino, Ilaria Radano (University Hospital of Salerno, Italy); Antonio Cittadini, Alberto Marra, Roberta D'Assante (Federico II University of Naples, Italy); Michele D'Alto, Paola Argiento (University of Campania 'Luigi Vanvitelli", Naples, Italy); Antonello D'Andrea (Umberto I' Hospital Nocera Inferiore, Italy); Francesco Ferrara, Carla Contaldi (Cava de' Tirreni and Amalfi Coast Hospital, University Hospital of Salerno, Italy); Luna Gargani, Matteo Mazzola, Marco Raciti (Institute of Clinical Physiology, CNR, Pisa, Italy); Santo Dellegrottaglie (Ospedale Medico-Chirurgico Accreditato Villa dei Fiori, Acerra - Naples, Italy); Nicola De Luca, Francesco Rozza, Valentina Russo (Hypertension Research Center, University Federico II of Naples, Italy); Giovanni Di Salvo (University of Padova, Italy; Imperial College, London, UK); Stefano Ghio, Stefania Guida (I.R.C.C.S. Policlinico San Matteo, Pavia, Italy); Ekkerard Grunig, Christina A. Eichstaedt (Heidelberg University Hospital, Germany); Marco Guazzi, Francesco Bandera, Valentina Labate (IRCCS Policlinico San Donato, University of Milan, Milan, Italy); André La Gerche (Baker Heart and Diabetes Institute, Melbourne, Australia); Giuseppe Limongelli, Giuseppe Pacileo, Marina Verrengia (University of Campania "Luigi Vanvitelli", Naples, Italy); Jaroslaw D. Kasprzak, Karina Wierzbowska Drabik (Bieganski Hospital, Medical University of Lodz Poland); Gabor Kovacs, Philipp Douschan (Medical University of Graz, Graz, Austria); Antonella Moreo, Francesca Casadei, Benedetta De Chiara, (Niguarda Hospital, Milan, Italy); Robert Naeije (Free University of Brussels, Brussels, Belgium); Ellen Ostenfeld (Lund University, Skåne University Hospital, Sweden); Gianni Pedrizzetti (Department of 
Engineering and Architecture, University of Trieste); Francesco Pieri, Fabio Mori, Alberto Moggi-Pignone (Azienda Ospedaliero-Universitaria Careggi, Florence, Italy); Lorenza Pratali (Institute of Clinical Physiology, CNR, Pisa, Italy); Nicola Pugliese (Department of Clinical and Experimental Medicine, University of Pisa, Italy); Brigida Ranieri, (IRCCS SDN, Diagnostic and Nuclear Research Institute, Naples, Italy); Rajan Saggar (UCLA Medical Center,Los Angeles, USA); Rajeev Saggar (Banner University Medical Center, Phoenix, Arizona, USA); Christine Selton-Suty, Olivier Huttin, Clément Venner (University Hospital of Nancy, France); Walter Serra, Francesco Tafuni (University Hospital of Parma, Italy); Anna Stanziola, Maria Martino, Giovanna Caccavo (Department of Respiratory Disease, Federico II University, Monaldi Hospital, Naples, Italy); István Szabó (University of Medicine and Pharmacy of Târgu Mureș, Târgu Mureș, Romania); Albert Varga, Gergely Agoston, (University of Szeged, Szeged, Hungary); Darmien Voilliot (Centre Hospitalier Lunéville, France); Olga Vriz (Heart Centre, King Faisal Specialist Hospital and Research Centre, Riyadh, Saudi Arabia); Mani Vannan, Sara Mobasseri, Peter Flueckiger, Shizhen Liu (Piedmont Heart Institute, USA).

\section{References:}

1. Lewis GD, Bossone E, Naeije R, Grünig E, Saggar R, Lancellotti P, Ghio S, Varga J, Rajagopalan S, Oudiz R, Rubenfire M. Pulmonary vascular hemodynamic response to exercise in cardiopulmonary diseases. Vol. 128, Circulation 2013; p. 1470-9.

2. Naeije R, Saggar R, Badesch D, Rajagopalan S, Gargani L, Rischard F, Ferrara F, Marra AM, D' Alto M, Bull TM, Saggar R, Grünig E, Bossone E. Exercise-induced pulmonary hypertension. Translating pathophysiological concepts into clinical practice. Chest 2018 Jan 31.

3. Rudski LG, Gargani L, Armstrong WF, Lancellotti P, Lester SJ, Grunig E, D'Alto M, Aneq MA, Ferrara F, Saggar R, Saggar R, Naeije R, Picano E, Schiller NB, Bossone E. Stressing the Cardiopulmonary Vascular System: The Role of Echocardiography. JASE 2018; 31(5):527-550.

4. Bossone E, D'Andrea A, D'Alto M, Citro R, Argiento P, Ferrara F, Cittadini A, Rubenfire M, Naeije R. Echocardiography in pulmonary arterial hypertension: from diagnosis to prognosis. J Am Soc Echocardiogr. 2013 Jan;26(1):1-14.

5. Ferrara F, Gargani L, Ostenfeld E, D'Alto M, Kasprzak J, Voilliot D, Selton-Suty C, Vriz O, Marra AM, Argiento P, Stanziola AA, Cittadini A, D'Andrea A, Bossone E. Imaging the right heart pulmonary circulation unit: Insights from advanced ultrasound techniques. Echocardiography. 2017 Aug;34(8):1216-1231.

6. Ferrara F, Gargani L, Armstrong WF, Agoston G, Cittadini A, Citro R, D'Alto M, D'Andrea A, Dellegrottaglie S, De Luca N, Di Salvo G, Ghio S, Grünig E, Guazzi M, Kasprzak JD, Kolias TJ, Kovacs G, Lancellotti P, La Gerche A, Limongelli G, Marra AM, Moreo A, Ostenfeld E, Pieri F, Pratali L, Rudski LG, Saggar R, Saggar R, Scalese M, Selton-Suty C, Serra W, Stanziola AA, Voilliot D, Vriz O, Naeije R, Bossone E. The Right Heart International Network (RIGHT-NET): Rationale, Objectives, Methodology, and Clinical Implications. Heart Fail Clin. 2018 Jul;14(3):443-465.

7. Bossone E, Gargani L. The RIGHT Heart International NETwork (RIGHT-NET): A Road Map Through the Right Heart-Pulmonary Circulation Unit. Heart Fail Clin. 2018 Jul;14(3)

8. Lang RM, Badano LP, Mor-Avi V, Afilalo J, Armstrong A, Ernande L, et al. Recommendations for cardiac chamber quantification by echocardiography in adults: an update from the American Society of Echocardiography and the European Association of Cardiovascular Imaging. J Am Soc Echocardiogr 2015; 28:1-39.

9. Nagueh SF, Smiseth OA, Appleton CP, Byrd BF 3rd, Dokainish H, Edvardsen T, Flachskampf FA, Gillebert TC, Klein AL, Lancellotti P, Marino P, Oh JK, Popescu BA, Waggoner AD. Recommendations for the Evaluation of Left Ventricular Diastolic Function by Echocardiography: An Update from the American Society of Echocardiography and the European Association of Cardiovascular Imaging. J Am Soc Echocardiogr. 2016 Apr;29(4):277-314.

10. Rudski LG, Lai WW, Afilalo J, et al. Guidelines for the echocardiographic assessment of the right heart in adults: a report from the American Society of Echocardiography endorsed by the European Association of Echocardiography, a registered branch of the European Society of Cardiology, and the 
Canadian Society of Echocardiography. J Am Soc Echocardiogr 2010;23:685-713.

11. Lancellotti P, Pellikka PA, Budts W, Chaudhry FA, Donal E, Dulgheru R, Edvardsen T, Garbi M, Ha JW, Kane GC, Kreeger J, Mertens L, Pibarot P, Picano E, Ryan T, Tsutsui JM, Varga A. The Clinical Use of Stress Echocardiography in Non-Ischaemic Heart Disease: Recommendations from the European Association of Cardiovascular Imaging and the American Society of Echocardiography. J Am Soc Echocardiogr. 2017 Feb;30(2):101-138.

12. Galiè N, Humbert M, Vachiery JL, Gibbs S, Lang I, Torbicki A, Simonneau G, Peacock A, Vonk Noordegraaf A, Beghetti M, Ghofrani A, Gomez Sanchez MA, Hansmann G, Klepetko W, Lancellotti P, Matucci M, McDonagh T, Pierard LA, Trindade PT, Zompatori M, Hoeper M, Aboyans V, Vaz Carneiro A, Achenbach S, Agewall S, Allanore Y, Asteggiano R, Paolo Badano L, Albert Barberà J, Bouvaist H, Bueno H, Byrne RA, Carerj S, Castro G, Erol Ç, Falk V, Funck-Brentano C, Gorenflo M, Granton J, Iung B, Kiely DG, Kirchhof P, Kjellstrom B, Landmesser U, Lekakis J, Lionis C, Lip GY, Orfanos SE, Park MH, Piepoli MF, Ponikowski P, Revel MP, Rigau D, Rosenkranz S, Völler H, Luis Zamorano J. 2015 ESC/ERS Guidelines for the diagnosis and treatment of pulmonary hypertension: The Joint Task Force for the Diagnosis and Treatment of Pulmonary Hypertension of the European Society of Cardiology (ESC) and the European Respiratory Society (ERS): Endorsed by: Association for European Paediatric and Congenital Cardiology (AEPC), International Society for Heart and Lung Transplantation (ISHLT). Eur Heart J. 2016 Jan 1;37(1):67-119.

13. Pellikka PA, Nagueh SF, Elhendy AA, Kuehl CA, Sawada SG. American Society of Echocardiography recommendations for performance, interpretation, and application of stress echocardiography. J Am Soc Echocardiogr 2015;20:1021-41.

14. Popescu BA, Stefanidis A, Nihoyannopoulos P, Fox KF, Ray S, Cardim N, Rigo F, Badano LP, Fraser AG, Pinto F, Zamorano JL, Habib G, Maurer G, Lancellotti P, Andrade MJ, Donal E, Edvardsen T, Varga A. Updated standards and processes for accreditation of echocardiographic laboratories from The European Association of Cardiovascular Imaging. Eur Heart J Cardiovasc Imaging. 2014 Jul;15(7):71727.

15. Patton DM, Enzevaie A, Day A, Sanfilippo A, Johri AM. A quality control exercise in the echo laboratory: Reduction in inter-observer variability in the interpretation of pulmonary hypertension. Echocardiography. 2017 Dec;34(12):1882-1887.

16. Armstrong AC, Ricketts EP, Cox C, Adler P, Arynchyn A, Liu K, Stengel E, Sidney S, Lewis CE, Schreiner PJ, Shikany JM, Keck K, Merlo J, Gidding SS, Lima JA. Quality Control and Reproducibility in M-Mode, Two-Dimensional, and Speckle Tracking Echocardiography Acquisition and Analysis: The CARDIA Study, Year 25 Examination Experience. Echocardiography. 2015 Aug;32(8):1233-40.

17. D'Andrea A, Stanziola AA, Saggar R, Saggar R, Sperlongano S, Conte M, D'Alto M, Ferrara F, Gargani L, Lancellotti P, Bossone E; RIGHT Heart International NETwork (RIGHT-NET) Investigators. Right Ventricular Functional Reserve in Early-Stage Idiopathic Pulmonary Fibrosis: An Exercise Two-Dimensional Speckle Tracking Doppler Echocardiography Study. Chest. 2019 Feb;155(2):297-306.

18. Argiento P, Vanderpool RR, Mulè M, Russo MG, D'Alto M, Bossone E, et al. Exercise Stress Echocardiography of the Pulmonary Circulation: Limits of Normal and Sex Differences. Chest. 2012 Nov 26;142(5):1158-65.

19. D'Alto M, Pavelescu A, Argiento P, Romeo E, Correra A, Di Marco GM, et al. Echocardiographic assessment of right ventricular contractile reserve in healthy subjects. Echocardiography 2017;34: 61-8.

20. Kusunose K, Popović ZB, Motoki H, Marwick TH. Prognostic significance of exercise-induced right ventricular dysfunction in asymptomatic degenerative mitral regurgitation. Circ Cardiovasc Imaging. 2013 Mar 1;6(2):167-76.

21. Wierzbowska-Drabik K, Picano E, Bossone E, Ciampi Q, Lipiec P, Kasprzak JD. The feasibility and clinical implication of tricuspid regurgitant velocity and pulmonary flow acceleration time evaluation for pulmonary pressure assessment during exercise stress echocardiography. Eur Heart J Cardiovasc Imaging. 2019 Sep 1;20(9):1027-1034.

22. Naeije R, Torbicki A. More on the noninvasive diagnosis of pulmonary hypertension: Doppler echocardiography revisited. Eur Respir J. 1995 Sep;8(9):1445-9. 
23. Ling LF, Obuchowski NA, Rodriguez L, Popovic Z, Kwon D, Marwick TH. Accuracy and interobserver concordance of echocardiographic assessment of right ventricular size and systolic function: a quality control exercise. J Am Soc Echocardiogr. 2012 Jul;25(7):709-13.

Table 1. Demographic and clinical characteristics of 10 subjects included in quality control procedure.

\begin{tabular}{ll}
\hline Variable & Value Mean $\pm \mathrm{SD}$ \\
\hline Age (years) & $67.2 \pm 11.3$ \\
Sex (male/female) & $2 / 8$ \\
$\mathrm{BSA}\left(\mathrm{m}^{2}\right)$ & $1.7 \pm 0.2$ \\
BMI $\left(\mathrm{Kg} / \mathrm{m}^{2}\right)$ & $25.2 \pm 2.2$ \\
Systolic blood pressure $(\mathrm{mmHg})$ & $129 \pm 24$ \\
Diastolic blood pressure $(\mathrm{mmHg})$ & $77 \pm 12$ \\
Heart rate (bpm) & $74 \pm 11$ \\
Diagnosis & \\
Healthy subjects & 1 \\
PAH & 1 \\
CTD & 1 \\
CHD & 1 \\
Patients with CAD risk factors & 2 \\
LHD & 2 \\
Lung disease & 1 \\
Post-PE & 1 \\
\hline
\end{tabular}

BSA, body surface area; BMI, Body Mass Index; CAD, coronary artery disease; CHD, congenital heart disease; CTD, connective tissue disease; LHD, left heart disease (coronary artery disease and heart failure); PAH, pulmonary arterial hypertension; Post-PE, post-pulmonary embolism; risk factors (hypertension, dyslipidaemia); SD, standard deviation. Data are expressed as number, mean $\pm \mathrm{SD}$.

Table 2. List of parameters measured in the quality control procedure

Left Chambers Parameters

\begin{tabular}{|c|c|c|c|c|c|c|}
\hline & Parameters & Rest & $50 \mathrm{~W}$ & Peak & Rec 5min & Images \\
\hline M-Mode & $\operatorname{LVEDD}(\mathrm{mm})$ & & & & & \\
\hline \multirow{4}{*}{$\begin{array}{l}\text { Echocardiog- } \\
\text { raphy }\end{array}$} & IVS (mm) & & & & & \\
\hline & $\mathrm{PWT}(\mathrm{mm})$ & & & & & \\
\hline & LVESD (mm) & & & & & \\
\hline & LVOT $(\mathrm{mm})$ & & & & & \\
\hline \multirow{9}{*}{$\begin{array}{l}\text { 2D- } \\
\text { Echocardiog- } \\
\text { raphy }\end{array}$} & LVEDV 4-CH & & & & & \\
\hline & (ml) LVESV & & & & & \\
\hline & 4-CH (ml) & & & & & \\
\hline & LVEDV 2-CH & & & & & \\
\hline & (ml) LVESV & & & & & \\
\hline & $2-\mathrm{CH}(\mathrm{ml})$ & & & & & \\
\hline & LA volume & & & & & \\
\hline & 4-CH (ml) LA & & & & & \\
\hline & $\begin{array}{l}\text { volume } 2-\mathrm{CH} \\
(\mathrm{ml})\end{array}$ & & & & & \\
\hline
\end{tabular}




\begin{tabular}{|c|c|c|c|c|c|c|}
\hline & Parameters & Rest & $50 \mathrm{~W}$ & Peak & Rec 5min & Images \\
\hline $\begin{array}{l}\text { Doppler- } \\
\text { Echocardiog- } \\
\text { raphy }\end{array}$ & $\begin{array}{l}\text { Mitral E and } \\
\text { A }(\mathrm{cm} / \mathrm{s}), \text { DT } \\
(\mathrm{ms}) \\
\text { Mitral } \\
\text { lateral and } \\
\text { septal e', a', } \\
\text { s'TDI } \\
(\mathrm{cm} / \mathrm{s}) \\
\text { Aortic Peak } \\
\text { Vel }(\mathrm{cm} / \mathrm{s}) \\
\text { LVOT VTI } \\
(\mathrm{cm})\end{array}$ & & & & & \\
\hline
\end{tabular}

\section{B. Right Chambers Parameters}

\begin{tabular}{|c|c|c|c|c|c|c|}
\hline & Parameters & Rest & $50 \mathrm{~W}$ & Peak & Rec 5 min & Images \\
\hline $\begin{array}{l}\text { M-Mode } \\
\text { Echo- } \\
\text { cardiography }\end{array}$ & TAPSE (mm) & & & & & \\
\hline $\begin{array}{l}\text { 2D- Echo- } \\
\text { cardiography }\end{array}$ & $\begin{array}{l}\text { RV basal and } \\
\text { mid diameter } \\
(\mathrm{mm}) \\
\text { RVED area } \\
\left(\mathrm{cm}^{2}\right) \text { RVES } \\
\text { area }\left(\mathrm{cm}^{2}\right) \\
\text { RA area } \\
\left(\mathrm{cm}^{2}\right) \text { and } \\
\text { Volume }(\mathrm{ml}) \\
\text { RVOT }(\mathrm{mm}) \\
\text { PA diameter } \\
(\mathrm{mm}) \\
\text { IVC }(\text { mm }) \text { and } \\
\text { collassability }\end{array}$ & & & & & \\
\hline $\begin{array}{l}\text { Doppler- } \\
\text { Echocardiog- } \\
\text { raphy }\end{array}$ & $\begin{array}{l}\text { RVOT AcT } \\
(\mathrm{m} / \mathrm{s}) \text { RVOT } \\
\text { VTI }(\mathrm{cm}) \\
\text { RV E and A } \\
(\mathrm{cm} / \mathrm{s}) \\
\text { RV e', a', S' } \\
\text { TDI } \\
\text { TRV }(\mathrm{cm} / \mathrm{s}) \\
\text { RV-RA } \\
\text { gradient } \\
(\mathrm{mmHg})\end{array}$ & & & & & \\
\hline
\end{tabular}

AcT, acceleration time; ED, end-diastolic; ES, end-systolic; IVC, inferior vena cava; PA, pulmonary artery; RA, right atrial; Rec, recovery; RV, right ventricular; RVOT, right ventricular outflow tract; TAPSE, tricuspid annular plane excursion; TDI, tissue Doppler imaging; TRV, trans-tricuspid valve regurgitation velocity; 
VTI, velocity time integral.

Table 3. Accuracy, ICC and $95 \%$ Confidence Interval of each Center for all parameters.

\begin{tabular}{lllll}
\hline Centers & Accuracy (\%) & ICC & $\begin{array}{l}\text { 95\% Confidence } \\
\text { Interval } \\
\text { Lower bound }\end{array}$ & $\begin{array}{l}\text { 95\% Confidence } \\
\text { Interval } \\
\text { Upper bound }\end{array}$ \\
Center 1 & & & 0.999 & 1.000 \\
Center 2 & 100 & 0.99 & 0.991 & 0.997 \\
Center 3 & 99.9 & 0.99 & 0.991 & 0.998 \\
Center 4 & 99.7 & 0.99 & 0.992 & 0.998 \\
Center 5 & 99.8 & 0.99 & 0.992 & 0.997 \\
Center 6 & 99.9 & 0.99 & 0.993 & 0.998 \\
Center 7 & 99.7 & 0.99 & 0.987 & 0.995 \\
Center 8 & 99.9 & 0.99 & 0.988 & 0.996 \\
Center 9 & 99.6 & 0.99 & 0.975 & 0.990 \\
Center 10 & 99.9 & 0.98 & 0.975 & 0.996 \\
Center 11 & 99.7 & 0.98 & 0.988 & 0.995 \\
Center 12 & 99.9 & 0.99 & 0.990 & 0.997 \\
Center 13 & 99.7 & 0.99 & 0.994 & 0.998 \\
Center 14 & 100 & 0.99 & 0.999 & 1.000 \\
Center 15 & 100 & 0.99 & 0.993 & 0.998 \\
Center 16 & 99.8 & 0.99 & 0.999 & 1.000 \\
Center 17 & 100 & 0.99 & 0.999 & 1.000 \\
Center 18 & 100 & 0.99 & 0.999 & 0.973 \\
Center 19 & 100 & 0.99 & 0.935 & \\
\hline
\end{tabular}

$\mathrm{ICC}=$ Intraclass Correlation Coefficient.

Table 4. Accuracy, ICC and 95\% Confidence Interval of each Center for all parameters at rest and peak.

\begin{tabular}{|c|c|c|c|c|c|c|c|c|}
\hline Centers & $\begin{array}{l}\text { Rest } \\
\text { Accuracy } \\
(\%)\end{array}$ & $\begin{array}{l}\text { Rest } \\
\text { ICC }\end{array}$ & $\begin{array}{l}\text { Rest } \\
95 \% \\
\text { Confi- } \\
\text { dence } \\
\text { Interval } \\
\text { Lower } \\
\text { bound }\end{array}$ & $\begin{array}{l}\text { Rest } \\
95 \% \\
\text { Confi- } \\
\text { dence } \\
\text { Interval } \\
\text { Upper } \\
\text { bound }\end{array}$ & $\begin{array}{l}\text { Peak } \\
\text { Accuracy } \\
(\%)\end{array}$ & $\begin{array}{l}\text { Peak } \\
\text { ICC }\end{array}$ & $\begin{array}{l}\text { Peak } \\
95 \% \\
\text { Confi- } \\
\text { dence } \\
\text { Interval } \\
\text { Lower } \\
\text { bound }\end{array}$ & $\begin{array}{l}\text { Peak } \\
95 \% \\
\text { Confi- } \\
\text { dence } \\
\text { Interv } \\
\text { Upper } \\
\text { bound }\end{array}$ \\
\hline $\begin{array}{l}\text { Center } \\
1\end{array}$ & 100 & 0.99 & 0.999 & 1.000 & 100 & 0.99 & 0.999 & 1.000 \\
\hline $\begin{array}{l}\text { Center } \\
2\end{array}$ & 99.8 & 0.99 & 0.978 & 0.993 & 99.8 & 0.99 & 0.990 & 0.999 \\
\hline $\begin{array}{l}\text { Center } \\
3\end{array}$ & 99.4 & 0.99 & 0.982 & 0.997 & 99.9 & 0.99 & 0.994 & 0.999 \\
\hline $\begin{array}{l}\text { Center } \\
4\end{array}$ & 99.8 & 0.99 & 0.983 & 0.997 & 99.9 & 0.99 & 0.993 & 0.999 \\
\hline $\begin{array}{l}\text { Center } \\
5\end{array}$ & 99.7 & 0.99 & 0.984 & 0.995 & 99.9 & 0.99 & 0.994 & 0.999 \\
\hline $\begin{array}{l}\text { Center } \\
6\end{array}$ & 99.8 & 0.99 & 0.994 & 0.999 & 99.9 & 0.99 & 0.993 & 0.999 \\
\hline
\end{tabular}




\begin{tabular}{|c|c|c|c|c|c|c|c|c|}
\hline $\begin{array}{l}\text { Center } \\
7\end{array}$ & 99.9 & 0.99 & 0.991 & 0.997 & 99.9 & 0.99 & 0.993 & 0.999 \\
\hline $\begin{array}{l}\text { Center } \\
8\end{array}$ & 99.6 & 0.99 & 0.981 & 0.995 & 100 & 0.99 & 0.998 & 0.999 \\
\hline $\begin{array}{l}\text { Center } \\
9\end{array}$ & 99.8 & 0.98 & 0.972 & 0.991 & 100 & 0.99 & 0.979 & 0.996 \\
\hline $\begin{array}{l}\text { Center } \\
10\end{array}$ & 99.6 & 0.98 & 0.973 & 0.986 & 99.8 & 0.99 & 0.978 & 0.996 \\
\hline $\begin{array}{l}\text { Center } \\
11\end{array}$ & 99.9 & 0.99 & 0.990 & 0.997 & 100 & 0.99 & 0.975 & 0.996 \\
\hline $\begin{array}{l}\text { Center } \\
12\end{array}$ & 99.6 & 0.99 & 0.982 & 0.997 & 99.9 & 0.99 & 0.990 & 0.998 \\
\hline $\begin{array}{l}\text { Center } \\
13\end{array}$ & 100 & 0.99 & 0.995 & 0.999 & 100 & 0.99 & 0.996 & 0.999 \\
\hline $\begin{array}{l}\text { Center } \\
14\end{array}$ & 99.9 & 0.99 & 0.998 & 0.999 & 100 & 0.99 & 0.998 & 0.999 \\
\hline $\begin{array}{l}\text { Center } \\
15\end{array}$ & 99.8 & 0.99 & 0.990 & 0.997 & 99.9 & 0.99 & 0.991 & 0.999 \\
\hline $\begin{array}{l}\text { Center } \\
16\end{array}$ & 100 & 0.99 & 0.999 & 1.000 & 99.9 & 0.99 & 0.998 & 0.999 \\
\hline $\begin{array}{l}\text { Center } \\
17\end{array}$ & 99.9 & 0.99 & 0.998 & 0.999 & 100 & 0.99 & 0.998 & 0.999 \\
\hline $\begin{array}{l}\text { Center } \\
18\end{array}$ & 100 & 0.99 & 0.999 & 1.000 & 100 & 0.99 & 0.998 & 0.999 \\
\hline $\begin{array}{l}\text { Center } \\
19\end{array}$ & 99.9 & 0.99 & 0.975 & 0.992 & 100 & 0.99 & 0.992 & 0.999 \\
\hline
\end{tabular}

ICC $=$ Intraclass Correlation Coefficient.

Table 5. Interobserver variability of main echocardiographic measurements of all participating centers at rest and at peak exercise.

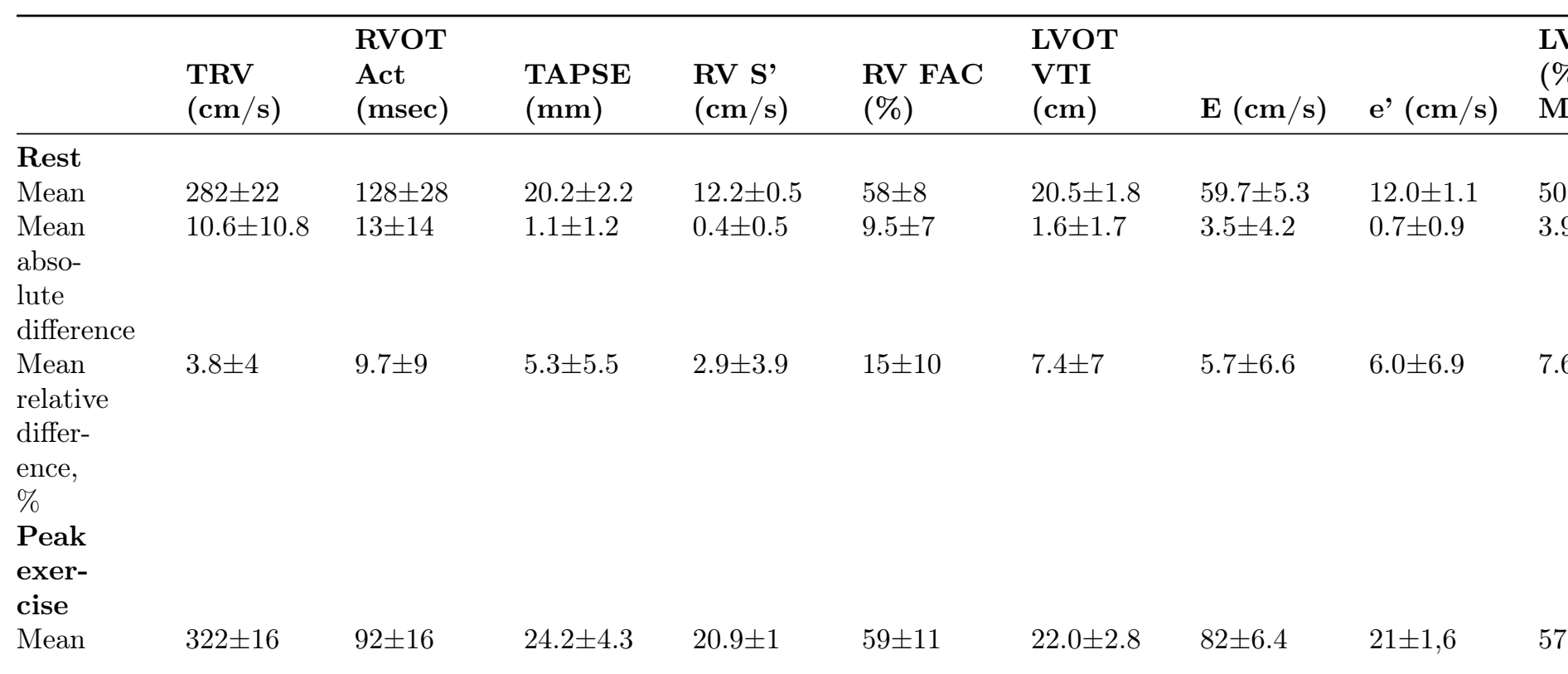




\begin{tabular}{|c|c|c|c|c|c|c|c|c|}
\hline & $\begin{array}{l}\text { TRV } \\
(\mathrm{cm} / \mathrm{s})\end{array}$ & $\begin{array}{l}\text { RVOT } \\
\text { Act } \\
(\mathrm{msec})\end{array}$ & $\begin{array}{l}\text { TAPSE } \\
(\mathrm{mm})\end{array}$ & $\begin{array}{l}\text { RV S' } \\
\left(\mathrm{cm} / \mathbf{s}^{\prime}\right)\end{array}$ & $\begin{array}{l}\text { RV FAC } \\
(\%)\end{array}$ & $\begin{array}{l}\text { LVOT } \\
\text { VTI } \\
(\mathrm{cm}) \\
\end{array}$ & $\mathrm{E}(\mathrm{cm} / \mathrm{s})$ & $\mathrm{e}^{\prime}(\mathrm{cm} / \mathrm{s})$ \\
\hline $\begin{array}{l}\text { Mean } \\
\text { abso- } \\
\text { lute } \\
\text { difference }\end{array}$ & $7.7 \pm 7.4$ & $11 \pm 11$ & $1.5 \pm 3$ & $0.6 \pm 0.8$ & $9.2 \pm 7.7$ & $2.2 \pm 2.4$ & $7.3 \pm 6.4$ & $1.4 \pm 1.2$ \\
\hline $\begin{array}{l}\text { Mean } \\
\text { relative } \\
\text { differ- } \\
\text { ence, } \\
\%\end{array}$ & $2.4 \pm 2.3$ & $12 \pm 13$ & $8 \pm 14$ & $2.9 \pm 3.4$ & $16 \pm 14$ & $9.6 \pm 10$ & $8.3 \pm 7.0$ & $6.5 \pm 5.1$ \\
\hline
\end{tabular}

Legend: Act, acceleration time; $\mathrm{CH}$, chamber; E, mitral early inflow velocity; e', early diastolic mitral annular lateral velocity; EF, ejection fraction; FAC, fractional area change; LVOT, left ventricular outflow tract; MOD, biplane method of disks (modified Simpson's rule); RV, right ventricle; RVOT, right ventricular outflow tract; S', tissue Doppler-derived tricuspid lateral annular systolic velocity; TAPSE, tricuspid annular plane systolic excursion; TRV, tricuspid regurgitation velocity; VTI, velocity time integral. 


\section{Quality Control Procedure}

1)

\begin{tabular}{|c|}
$\begin{array}{c}\text { Echo Core Lab } \\
\text { selects } 10 \text { exams with } \\
\text { measurements } \\
\text { (unanimous approval). }\end{array}$ \\
$\begin{array}{c}\text { CD with } \\
\text { DICOM clips } \\
\text { sent to }\end{array}$ \\
\hline
\end{tabular}

$$
\begin{gathered}
\text { Participating } \\
\text { Center }
\end{gathered}
$$
read the exams and fill the Excel file

3)
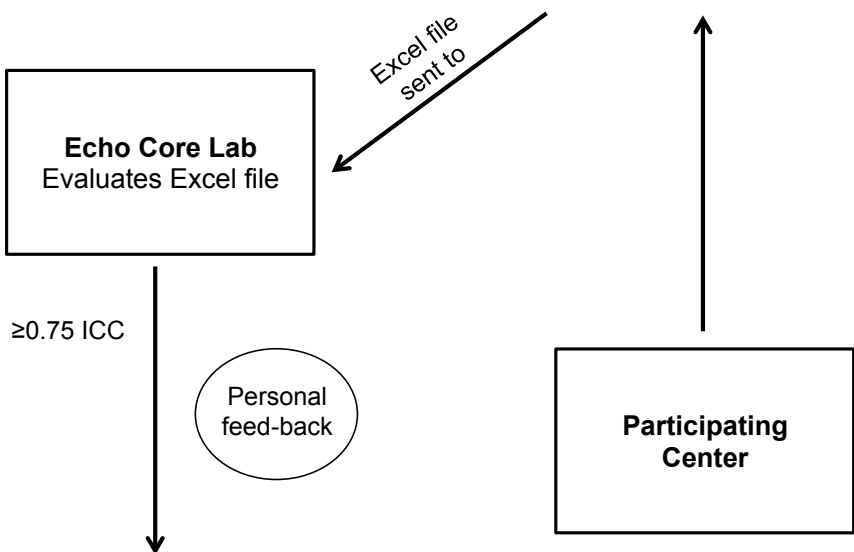

Step 2 and final QC APPROVED 

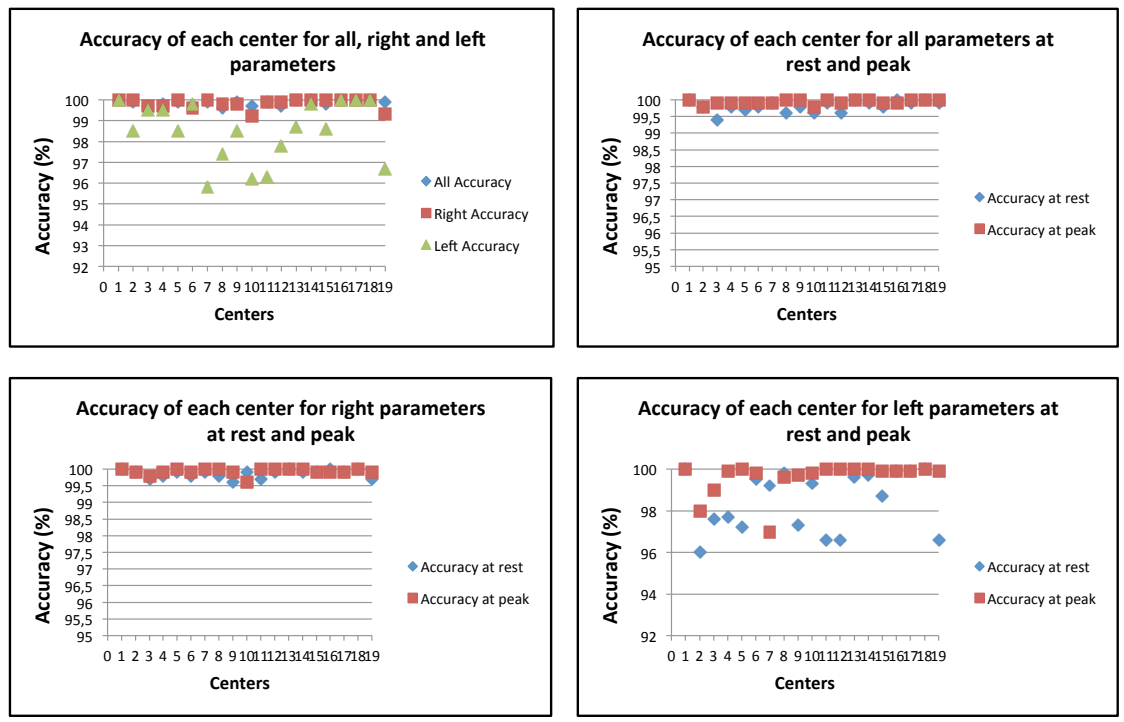